\title{
Intermittent Pneumatic Compression in Treatment of Chronic Venous Leg Ulcers: A Case Report and Review of Literature
}

\author{
Ali Kordzadeh, Attila Jonas, Yiannis P. Panayiotopoulos \\ Mid Essex Hospital Services NHS Trust, Department of Vascular \& Endovascular Surgery, Broomfield Hospital, \\ Essex, UK \\ Email: Alikordzadeh@gmail.com
}

Received 27 July 2014; revised 20 August 2014; accepted 3 September 2014

Copyright (C) 2014 by authors and Scientific Research Publishing Inc.

This work is licensed under the Creative Commons Attribution International License (CC BY). http://creativecommons.org/licenses/by/4.0/

(c) (i) Open Access

\begin{abstract}
Introduction: The benefit of intermittent pneumatic compression (IPC) for the prevention of venous thromboembolism and lymphedema has been well established in the literature. Recent evidence suggests that IPC plays a beneficial role in circulation, hemodynamic peripheral pump, intravascular coagulation and arterial skin perfusion. Despite such evidence, the use of IPC in the treatment of resistant and chronic venous leg ulcers, has received little attention in practice. Case Presentation: We would like to report the case of successfully treated chronic and bilateral venous leg ulcer in an obese patient with IPC application and a review of the literature. Results: The use of IPC as an adjuvant therapy to the traditional multilayered compression therapy permitted significant resolution of the ulcers, reduced secondary infection incidence and prevented ulcer recurrence. Conclusion: In obese, minimally mobile patients with venous ulcers not responding to the traditional multilayered compression therapy application of IPC, an adjuvant therapy is recommended.
\end{abstract}

\section{Keywords}

Intermittent Pneumatic Compression (IPC), Chronic Venous Leg Ulcers, Bilateral Venous Leg Ulcer Management, Compression Therapy, Obese Patient, Follow-Up

\section{Introduction}

Chronic leg ulcers are a common condition that affects $3 \%$ to $5 \%$ of the aging population ( $>65$ ) and results in poor quality of life. In addition, they impose a significant economical burden on health services. For instance, in 
the National Health Service (NHS) UK alone, the estimated cost of therapy for chronic leg ulceration is around $£ 290$ million per annum. Amongst etiologies, venous disease contributes to $72 \%$ of chronic leg ulcers, where as mixed arterio-venous disease (14.5\%), arterial insufficiencies and other medical conditions play a less attributing role (Table 1). Their care demands a wide range of input from various specialties on an inpatient and outpatient basis (topical agents, dressings, multilayered compression bandages, graduated compression stockings, vein stripping and skin grafting). Intermittent pneumatic compression (IPC) has widely been used for the prophylaxis of venous thromboembolism and lymphedema. However, its use in chronic venous ulceration has received little attention [1]-[3]. The IPC deploys an air pump to intermittently inflate and deflate sleeves that envelop the legs. There are a number of variations in the application of intermittent pneumatic compression, using single or multiple sleeves or by using different types of pumps and compression cycles. Herein, we would like to report a successfully treated case of a chronic and bilateral lower limb venous ulceration in an obese patient using intermittent pneumatic compression (IPC) as an adjuvant therapy to the traditional multilayered compression dressing.

\section{Case Presentation}

A 71-year-old female patient with a past medical history of hypertension, chronic obstructive pulmonary disease (COPD) and right hip replacement was referred to the vascular department with bilateral non-healing and worsening chronic venous leg ulcers. The patient weighed 210 kilograms and her mobility was limited to a maximum of 10 meters with the help of a Zimmer frame. She suffered from 4 episode of cellulitis over a short period of 60 days with no resolution through traditional multilayered compression therapy. The arterial duplex examination revealed tri-phasic popliteal and biphasic posterior and anterior Tibial artery with no evidence of venous insufficiency and competent veins bilaterally. Hematological investigation was unremarkable. The ankle reflex and peripheral neurological examination were also unremarkable. On examination she had bilateral circumferential ulcer with significant and constant exudation. She was started on a 7-day course of antibiotics according to the sensitivity of the swabs taken prior to her admission. The patient was subjected to a bilateral multilayered compression bandaging of $20-40 \mathrm{mmHg}$ plus an intermittent pneumatic compression (IPC) set at $40 \mathrm{mmHg}$ with 3 cycles per minute through rapid inflation. Over the period of 8 weeks she was regularly consulted by physiotherapy and continued to have the IPC for approximately 7 - 8 hours a day. There was significant resolution of the ulcers and improved mobility (independent 20 meters). The patient was discharged with the IPC and advised to use it at home to optimize outcome and avoid recurrence. A 3-month follow-up, the patient showed near total resolution of the ulcers with no further episodes of cellulitis (Figure 1).

\section{Discussion}

The underlying pathology of venous leg ulcers is chronic insufficiency due to venous hypertension. This is the result of vein blockage, incompetency or in some cases both. They are more common in the elderly and female population [4]. To date, various hypothesis have been suggested about the process of ulceration. Amongst them, white cell rheology, macromolecules, micro vascular ischemia and fibrin cuff remain the most referred ones in the literature (Table 2).

Table 1. Aetiology of leg ulcers.

- Venous insufficiency $(70=80 \%)$

- $\quad$ Mix disease (Arterio $=$ venous $(10=14 \%)$

- Arterial disease $(2=5 \%)$

- $\quad$ Lymphatics (2 = 3\%)

- Vasculitis (rheumatoid arthritis, scleroderma, SLE, Wegener's granulomatosis)

- Neuropathic (diabetes, peripheral neuropathy)

- Traumatic (burns, cold injury, radiation)

- Neoplastic (squamous or basal cell carcinoma, Marjolin's ulcer, melanoma)

- Sarcoidosis

- Pyoderma gangrenosum

- Others 
Table 2. Suggested hypothesis behind venous leg ulceration.

- White cell rheology: reduction in capillary blood flow results in trapping of white blood cells in the capillaries causing plugging and release of proteolytic enzymes, cytokine and free radicals leading to tissue ulceration.

- Macromolecules \& microvascular ischemia: venous ulceration sets a vicious cycle of tissue ischemia at micro vascular level by reducing the number of skin capillaries and flow thus trapping of matrix proteins and growth factors.

- Fibrin cuff: patients with chronic venous insufficiency are found to have peri-capillary fibrin cuffs acting as a barrier to oxygen perfusion.
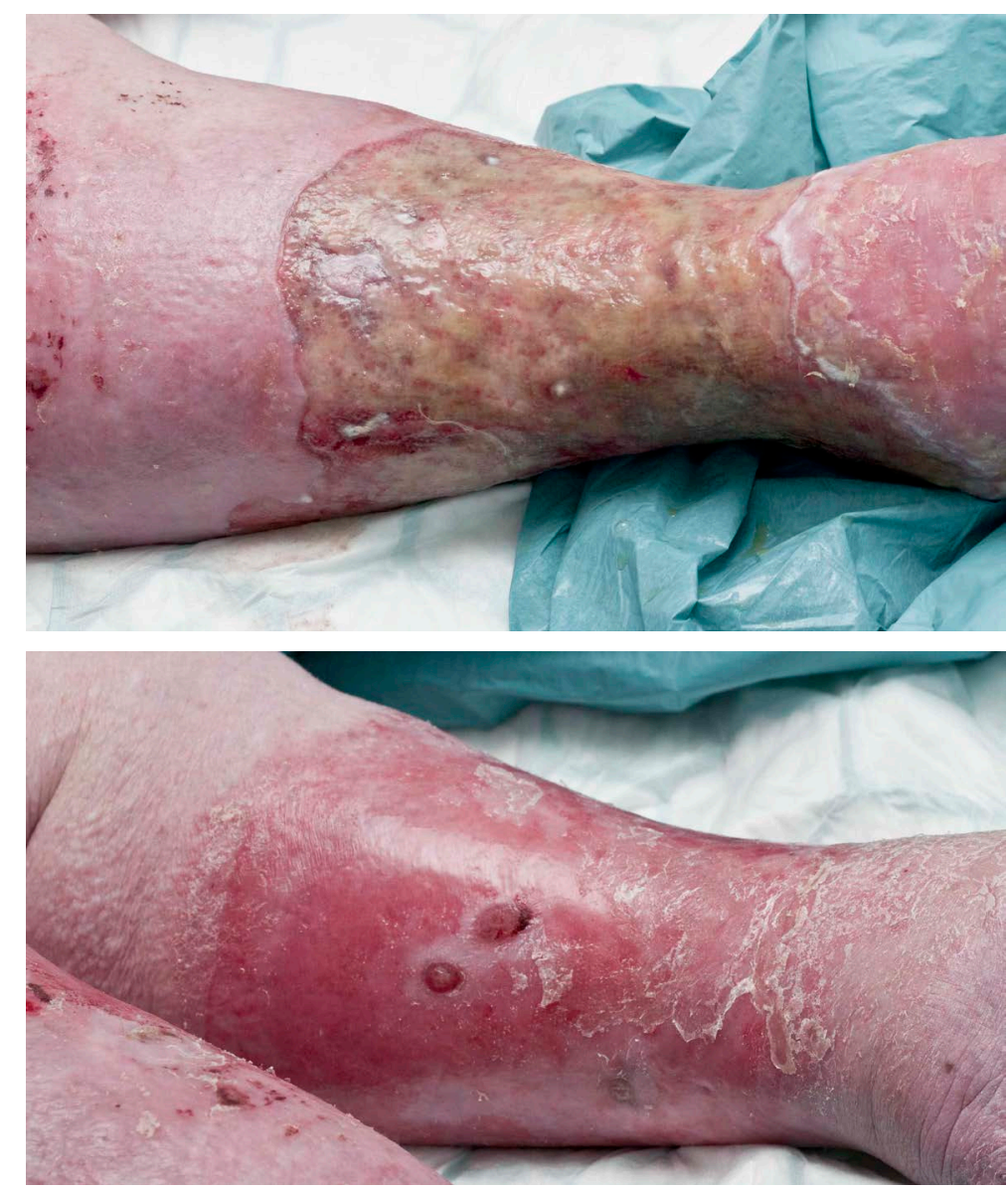

Figure 1. The pre- and post-IPC application status of the leg ulcers.

The overall treatment is aimed at reduction or avoidance of sustained venous hypertension [5]. The traditional and gold standard therapy is application of the multilayered compression dressing. This aims to improve the venous return by passive promotion of the peripheral hemodynamic pump (calf and the foot muscles) [6]. However, such routine practice is not necessarily applicable to large, longstanding and bilateral leg ulcers in obese and minimally mobile patients. For instances, the immobility as a consequence of chronicity and obesity will result in an ineffective or partial peripheral calf and pump action. Secondly, the elasticity or compression effect of dressing over the passage of time becomes inadequate and partial. Thirdly; such dressings are operator-dependent and application of uniform and constant pressure is not always achievable. Finally, failure to heal will cause a negative cycle of emotions and lack of overall patient compliance. In addition, multiple randomized controlled trials have shown successful treatment in only $37 \%$ to $55 \%$ of patients at 12 weeks by multilayered compression therapy alone [7] [8].

In 1981, McCulloch for the first time suggested that IPC could be a useful modality in the treatment of chronic venous leg ulcers [9]. It appears that IPC not only enhances the hemodynamic pump but also plays a significant role in promoting intravascular coagulation (Table 3). The use of IPC also increases the arterial skin perfu- 
Table 3. Beneficial physiological impact of IPC.

- Hemodynamic effects:

Decrease venous stasis.

Increase flow velocity in deep veins.

Positive contraction of calf pump.

Reduce leg edema.

- Hematological effects:

Increase fibrinolytic activity.

Increase tissue plasminogen activator ( $t \mathrm{PA})$.

- Tissue oxygen tension:

Increase transcutaneous oxygen tension (TcPO2).

Increase arterial skin perfusion.

sion and endogenous fibrinolysis. The overall impact creates an environment favoring wound healing [10]. In addition, rapid inflation as opposed to slow inflation over a longer period of time has shown to be more effective in healing (rapid IPC inflation days $=59$ vs. slow inflation IPC days $=100, p=0.001$ ) and pain management [11] [12].

The review by Nelson et al. in 2011 suggested no robust evidence supporting the use of IPC alone in the treatment of the chronic venous leg ulcers but the outcome was solely based on complete resolution of the ulcers rather than the ratio or percentage of wound healing over a period of time. In the same review, there appears to be some evidence to support faster wound healing when rapid inflation through IPC was applied [13]. This outcome was complimented by Cambria et al. study when IPC application showed increased overall healing and more so in complex and chronic cases [14].

It seems that IPC produces a favorable environment for wound healing in venous leg ulcers by various mechanisms (Table 2) but currently there is no consensus on the method of their application in the literature and practice. The overall management of a patient with chronic leg ulcer is complex and should not solely depend on compression therapy alone. Addressing other contributing factors like increase mobility through regular physiotherapy, enhancement of nutritional support, meticulous glycemic control, antibiotics, psychological support, patient education and selected venous surgery with or without skin grafting should also be considered to optimize the overall outcome.

\section{Conclusion}

Management of chronic venous leg ulcers is complex and demands a meticulous approach. In circumstances, where multilayered compression dressing in combination with other measures (physiotherapy, dietary, antibiotics, and patient education) fails to produce optimal results, application of IPC has shown to be beneficial and could be considered to optimize outcome. Preventing ulcer recurrence is equally as important as its initial treatment and the IPC application might result in their overall resolution, especially in obese patients where compliance to traditional multilayered compression therapy is not consistent and is highly operator-dependent.

\section{Conflict of Interest}

None.

\section{Consent}

Patient consent was obtained for this case report and accompanying images without disclosing patient information.

\section{References}

[1] Crane, J.S. and Cheshire, N.J.W. (2004) Chronic Ulceration of the Leg. Surgery, 22, 327-330.

[2] Chen, A.H., Frangos, S.G., Kilaru, S. and Sampio, B.E. (2001) Intermittent Pneumatic Compression Devices Physiology Mechanism of Action. European Journal of Vascular and Endovascular Surgery, 21, 383-392. http://dx.doi.org/10.1053/ejvs.2001.1348 
[3] Weingarten, M.S. (2001) State of the Art Treatment of Chronic Venous Disease. Clinical Infectious Diseases, 32, 949954. http://dx.doi.org/10.1086/319360

[4] Abade, L. and Lastoria, S. (2005) Venous Ulcer: Epidemiology, Physiology, Diagnosis and Treatment. International Journal of Dermatology, 44, 449-456. http://dx.doi.org/10.1111/j.1365-4632.2004.02456.x

[5] Greenwood, J.E., Edwards, A.T. and McCollum, C.N. (1995) The Possible Role of Ischemic Reperfusion in the Pathogenesis of Chronic Venous Ulceration. Wounds, 7, 211-219.

[6] Wound Healing Society (2006) Guidelines for the Treatment of Venous Ulcers. Wound Repair and Regeneration, 14, 649-662. http://dx.doi.org/10.1111/j.1524-475X.2006.00174.x

[7] Iglesias, C., Nelson, E.A., Cullum, N.A. and Torgerson, D.J. (VenUS Team) (2004) VenUS I: A Randomized Controlled Trial of Two Types of Bandage for Treating Venous Leg Ulcers. Health Technology Assessment, 8, 1-105.

[8] O’Brien, J.F., Grace, P.A., Perry, I.J., Hannigan, A., Clarke Moloney, M. and Burke, P.E. (2003) Randomized Clinical Trial and Economic Analysis of Four Layer Compression Bandaging for Venous Ulcer. British Journal of Surgery, 90, 794-798. http://dx.doi.org/10.1002/bjs.4167

[9] McCulloch, J.M. (1981) Intermittent Compression for the Treatment of Chronic Stasis Ulceration; a Case Report. Physical Therapy, 61, 1452-1453.

[10] Kearon, C., Kahn, S.R., Agnelli, G., Goldhaber, S., Raskob, G.E. and Comerota, A.J. (American College of Chest Physician) (2008) Antithrombotic Therapy for Venous Thromboembolism Disease: American College of Chest Physicians Evidence Based Clinical Practice Guidelines (8th Edition). Chest, 133, 453S-545S.

[11] Nikolovska, S., Arsovski, A., Damevska, K., Gocev, G. and Pavlova, L. (2005) Evaluation of Two Different Intermittent Compression Cycle Settings in the Healing of Venous Ulcers: A Randomized Trial. Medical Science Monitor, 11, 337-343.

[12] Shuler, J.J., Maibenco, T., Megerman, J., Ware, M. and Montalvo, J. (1996) Treatment of Chronic Venous Ulcers Using Sequential Gradient Intermittent Pneumatic Compression. Phlebology, 11, 111-116.

[13] Nelson, E.A., Mani, R., Thomas, K. and Vowden, K. (2011) Intermittent Pneumatic Compression for Treating Venous Leg Ulcers. Cochrane Database of Systematic Review, 2, Article ID: CD001899. http://dx.doi.org/10.1002/14651858.CD001899.pub3

[14] Cambria, R.P. (2011) Intermittent Pneumatic Compression: Physiologic and Clinical Basis to Improve Management of Venous Leg Ulcers. Journal of Vascular Surgery, 52, 1121-1129. 
Scientific Research Publishing (SCIRP) is one of the largest Open Access journal publishers. It is currently publishing more than 200 open access, online, peer-reviewed journals covering a wide range of academic disciplines. SCIRP serves the worldwide academic communities and contributes to the progress and application of science with its publication.

Other selected journals from SCIRP are listed as below. Submit your manuscript to us via either submit@scirp.org or Online Submission Portal.
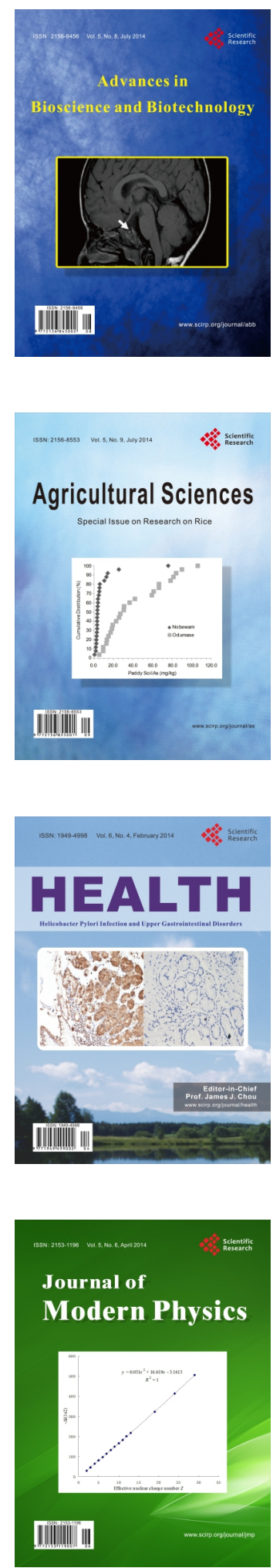
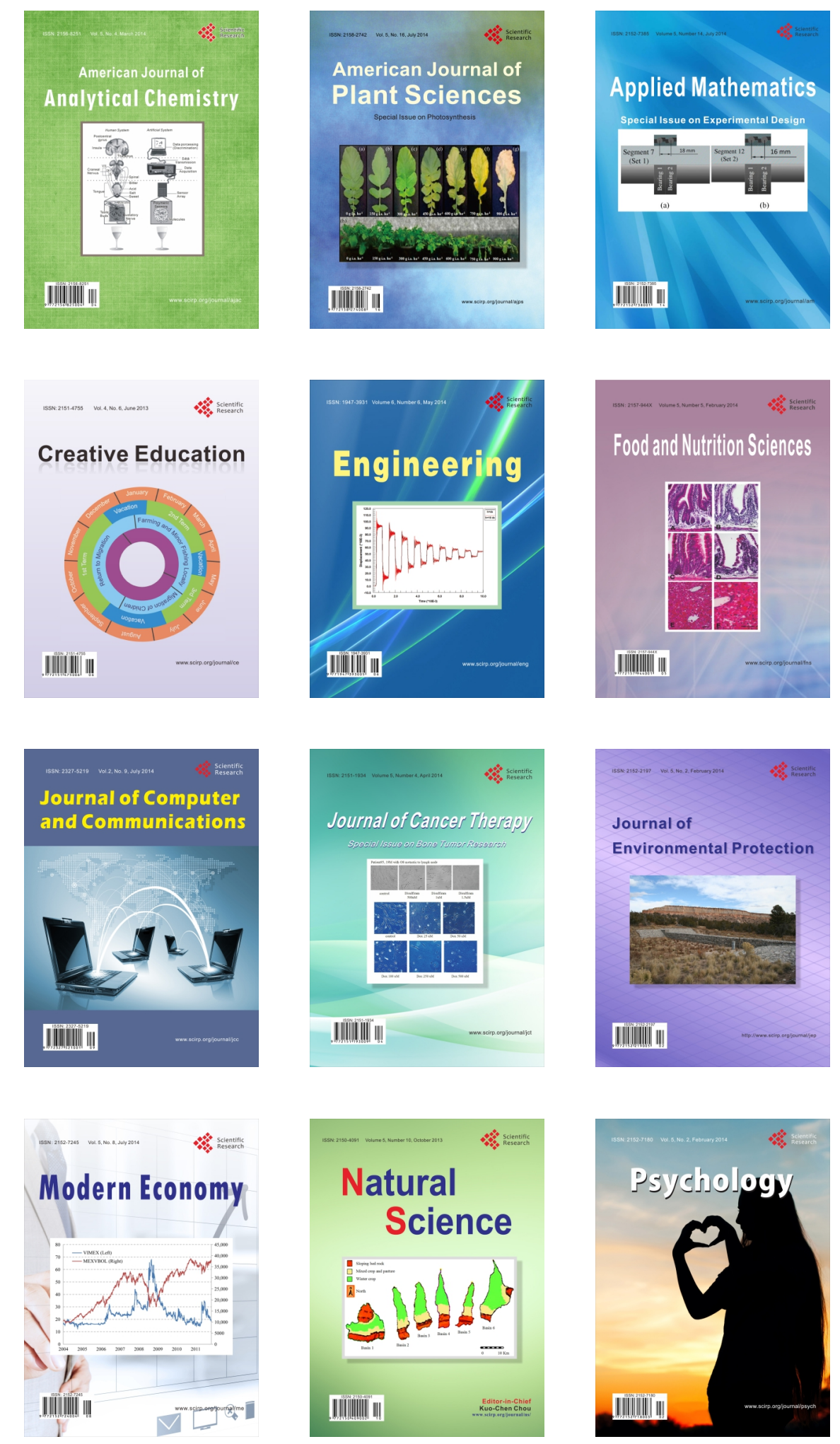